\title{
REFLEXÕES DE PASSAGEM SOBRE O LAZER: NOTAS SOBRE A PEDAGOGIA DA INDÚSTRIA CULTURAL
}

\author{
AleXANDRE FERNANDEZ VAZ*
}

\section{RESUMO}

O presente texto trata de alguns elementos da relação entre indústria cultural e lazer, compreendendo o segundo como parte indissociável da primeira. Para isso, o artigo retoma, em sua primeira parte, um pouco da origem do conceito, tal como foi desenvolvido por Theodor Adorno e Max Horkheimer. Logo depois, são citados alguns exemplos nos quais se materializam os esquemas da indústria cultural - a transmissão da Copa de 2002, a arena política contemporânea, um filme documentário, a indústria do culto ao corpo - para tentar verificar como esses esquemas formam uma constelação macabra que naturaliza os processos de dominação pelo entretenimento contemporâneo. Ao final, o texto realiza uma pequena incursão no tema do riso, expressão de uma dialética da civilização, do descontrole pulsional mediado racionalmente, mas também marca da esperança de uma natureza não conformada.

PALAVRAS-CHAVE: lazer - indústria cultural - Escola de Frankfurt - tempo livre - corpo - Theodor W. Adorno

\section{INTRODUÇÃO}

Os interesses reais do indivíduo ainda são suficientemente fortes para, dentro de certos limites, resistir à apreensão [Erfassung] total. Isto coincidiria com o prognóstico social, segundo o qual, uma sociedade, cujas condições fundamentais permanecem inalteradas, também não poderia ser totalmente integrada pela consciência. A coisa não funciona assim tão sem dificuldades, e menos no tempo livre, que, sem dúvida, envolve as pessoas, mas, segundo seu próprio conceito, não pode fazê-lo completamente sem que isso fosse demasiado para elas. Renun-

* Doutor em Ciências Humanas e Sociais pela Universidade de Hannover, professor do Departamento de Metodologia de Ensino e do Programa de Pós-graduação em Educação do Centro de Ciências da Educação da Universidade Federal de Santa Catarina, coordenador geral do Núcleo de Estudos e Pesquisas Educação e Sociedade Contemporânea e bolsista de Produtividade em Pesquisa do CNPq. 
cio a esboçar as conseqüências disso; penso, porém, que se vislumbra aí uma chance de emancipação que poderia, enfim, contribuir algum dia com sua parte para o tempo livre se transforme em liberdade [dass Freizeit in Freiheit umspringt].

(Theodor W. Adorno)

Gaz sentido falar em indústria cultural e lazer, uma vez que, se a 1 primeira é o espírito privilegiado do nosso tempo, o segundo só pode ser entendido como uma das faces da primeira. Isso só pode ser afirmado porque não se trata de pensar o lazer como "apropriado" pela indústria cultural, mas como sua face privilegiada. A indústria cultural não subtrai ou deforma o lazer, mas o constitui em relação ao trabalho como outra face da moeda da dominação social.

Desde final dos anos oitenta do século passado, temos uma profusão de textos que falam sobre indústria cultural e lazer, esporte e mídia. Muitas interpretações se equivocam na estruturação de seu argumento central: ou consideram a indústria cultural como uma força autônoma e demoníaca que absorve o esporte e o lazer, arrancando-lhes a suposta pureza original, ou equiparam-na com a mídia, em especial com a televisão, que é apenas uma de suas formas, sem dúvida importante. Vou tentar construir meu argumento em sentido alternativo, numa direção talvez algo ortodoxa: minha hipótese de trabalho é que o lazer simplesmente não pode ser pensado fora dos esquemas da indústria cultural, dos ardis reificadores dos esquemas de dominação e produção de subserviência, de servidão voluntária; que o "tempo livre", como paródia de si mesmo, é uma impossibilidade.

Para desenvolver estas idéias, divido meu texto ${ }^{1}$ em três partes: de início, relembro alguns elementos do conceito de indústria cultural, tal como foi desenvolvido pelos primeiros que o formularam, conhecidos representantes da Teoria Crítica da Sociedade da Escola de Frankfurt, Theodor W. Adorno e Max Horkheimer. Isso é importante para fazermos justiça aos autores da expressão, que se debruçam sobre o tema detalhadamente, em centenas de páginas, que vão do jazz ao cinema, do esporte à astrologia. É preciso delimitar o que entendemos quando pronunciamos a expressão indústria cultural, que se tornou um slogan - inclusive positivo! - utilizado para discorrer sobre a produção da cultura e do entretenimento em nosso tempo. Considero que, para os 
objetivos deste texto, é importante uma nota teórica inicial para evitar alguns mal-entendidos.

$\mathrm{Na}$ segunda parte, procuro apresentar alguns impasses do lazer sob o espírito do nosso tempo, em grande parte traduzíveis no conceito de indústria cultural. Tomo alguns exemplos de como a vida cotidiana é funcionalizada e "resolvida" nas esferas do entretenimento. Discuto, portanto, como a diversão acaba por determinar, num ritual macabro, as relações sociais que tentam se estruturar nos momentos supostamente alheios às atividades de trabalho.

$\mathrm{Na}$ última parte, faço algumas incursões sobre o tema do riso, para ver como ele apresenta um dos paradoxos humanos mais importantes: o descontrole que nos lembra a natureza dispersa, caótica, desorganizada, que se mostra espontânea frente ao trágico e ao cruel, mas também o que ele nos mostra como expressão de uma natureza que, por ainda não ser domesticada, nos dá, talvez, fragmentos da esperança de algo que, afinal, ainda possa existir fora dos esquemas de dominação.

\section{ELEMENTOS CONCEITUAIS DA INDÚSTRIA CULTURAL}

Quando Horkheimer e Adorno empregaram pela primeira vez a expressão indústria cultural, nos anos quarenta do século passado, em um dos livros mais importantes do pensamento contemporâneo - o conjunto de fragmentos filosóficos que compõe a Dialética do esclarecimento -, pretendiam esclarecer uma possível confusão. Disse Adorno (1997a), anos mais tarde, que não utilizaram o termo cultura de massas, já então bastante empregado, porque não queriam que o objeto a que se dedicavam fosse confundido com a cultura popular. Não se referiam, portanto, a uma cultura que vem das massas, mas, essencialmente, a um conjunto de artefatos produzido para as massas consumidoras. Tinham em mente o cinema, o rádio, as revistas ilustradas, seções de jornais diários e, algum tempo depois, a televisão.

O conceito indústria cultural procura compreender as condições de produção e reprodução social em uma de suas faces mais importantes, relacionada à mercadorização da cultura, sua banalização e reificação. O que nossos autores supunham como inteiramente novo - já que parece desde muito ter havido algum tipo de negócio com os artefatos culturais - é que a cultura passa a ser produzida na esfera da circulação e do consumo para o entretenimento e ocupação do "tempo livre". 
Não se trata, portanto, de expressar os mais sublimes e tensos sentimentos humanos, registrando, nas suas diversas formas, a dor, o sofrimento, a esperança de felicidade, o medo, o ódio, as paixões de todos os matizes, mostrando, portanto, para além do conceito, o que haveria de demasiadamente humano. Em lugar da esperança e da utopia, presentes na grande obra, a banalidade do já conhecido, a repetição incessante, os clichês, os lugares-comuns, os excessos, a redundância daquilo que é pouco complexo, o sempre igual repetido incessantemente como um círculo infernal. A pergunta não é pela diversidade, tomada por Adorno como expressão de resistência na permanência do particular, antídoto contra toda forma de coletivismo, mas sim por aquilo que aparenta ser diferente para, na verdade, continuar sendo a mesma coisa. Aquilo que, em sua formulação precisa, ao dizer que critica, obedece (ADORNO, 1997b).

Adorno (1997a) assegura que, em tempos de sociedade administrada e indústria cultural, a produção da cultura não é "também" mercadoria, mas é mercadoria antes de tudo. Universo da troca sacrificial atualizada em moeda e exploração do trabalho, o capitalismo força a equiparação do distinto, tornando intercambiável aquilo que, em princípio, deveria ser único e definitivo em sua expressão. Aparentada com a ciência moderna, a troca mercantil opera não mais por substitubilidade específica, como na magia, mas por fungibilidade universal (HORKEIMER; ADORNO, 1997).

Horkheimer e Adorno preocuparam-se não apenas com esta nova forma de produção, mas com seus clientes nos quais há que se desenvolver uma disposição e mesmo uma urgência psicofisiológica para o consumo, essencialmente no seu tempo disponível do trabalho - o conhecido "tempo livre" -, para que a lógica da exploração e do esgotamento se solidifique também extramuros do escritório, da fábrica, da sala de aula. Não por acaso, Adorno (1978) foi um crítico radical da defesa do tempo livre que faz esquecer que o trabalho em nossa sociedade é sinônimo de esgotamento, sofrimento e danificação. Em uma palavra, o estado falso de vida - aquele que a indústria cultural pretende tornar justificável - não autoriza ser adjetivado como humano (ADORNO, 1997c).

Esse estado falso de vida, que nos obriga a perguntar sobre o que resta sujeito na sociedade administrada, pode ser traduzido em algumas questões triviais: Afinal, por que é tão sedutor assistir aos programas do auditório? Ou à novela? Ou ao Jornal Nacional? Ou mesmo aos pro- 
gramas supostamente informativos, para "um público diferenciado", os das TVs a cabo? Por que nos é tão difícil, ao chegar a casa, depois de mais um dia de danação no escritório, na fábrica, na universidade, na escola, no clube, na repartição e - fatigados - não ligar a televisão? Por que sucumbimos frente à pornografia ou à tecnicalidade dos conselhos de "especialistas" nas revistas ilustradas, aqueles/as que nos ensinam como ter a "atitude" correta no mercado competitivo, a etiqueta das relações sexuais ou a série de exercícios que nos livrará da vergonha dos excessos do corpo exposto no verão? Por que os veículos da indústria cultural tanto nos seduzem?

Os mecanismos da indústria cultural procuram dar a seus consumidores aquilo que "eles querem", que já esperam. Um exemplo bastante eloqüente é o jornal diário alemão Bild, que se notabiliza pela divulgação de escândalos, crimes, fuxicos sexuais e futebol, e tem um slogan que, ironicamente, mostra bem o que se espera. Ele diz, em suas propagandas: Bild: dir, deine Meinung (Bild - que quer dizer "imagem" - para você, o que você já pensa). Nenhum esforço de compreensão deve ser exigido, aliás, todo empenho nessa direção deve ser vedado, qualquer relação com o objeto que demande reflexão ou mediação estética para além da superficialidade, deve ser denegada. Aos sentidos humanos é destinado um treinamento que faça responder a demandas específicas, cada vez mais dirigidas e previsíveis.

Cito dois trechos de Dialética do esclarecimento que são elucidativos quanto a esta situação, e também no que se refere ao que pode significar, contemporaneamente, divertir-se. Logo depois, passo à parte seguinte do texto, trazendo alguns exemplos de como se operam estas questões.

Atualmente, a atrofia da imaginação e da espontaneidade do consumidor cultural não precisa ser reduzida a mecanismos psicológicos. Os próprios produtos - e entre eles em primeiro lugar o mais característico, o filme sonoro - paralisam essas capacidades em virtude de própria constituição objetiva. São feitos de tal forma que sua apreensão adequada exige, é verdade, presteza, dom de observação, conhecimentos específicos, mas também de tal sorte que proíbem a atividade intelectual do espectador, se ele não quiser perder os fatos que desfilam velozmente diante de seus olhos. O esforço, contudo, está tão profundamente inculcado que não precisa ser atualizado em cada caso para recalcar a imaginação (HORKHEIMER; ADORNO, 1985, p. 119; 1997, p. 148). 
A diversão é o prolongamento do trabalho no capitalismo tardio. Ela é procurada por quem quer escapar ao processo de trabalho mecanizado, para se pôr de novo em condições de enfrentá-lo. Mas, ao mesmo tempo, a mecanização atingiu um tal poderio sobre a pessoa em seu lazer e sobre sua felicidade, ela determina tão profundamente a fabricação de mercadorias destinadas à diversão, que esta pessoa não pode mais perceber outra coisa senão as cópias que reproduzem o próprio processo de trabalho. O pretenso conteúdo não passa de uma fachada desbotada; o que fica gravado é a seqüência automatizada de operações padronizadas. Ao processo de trabalho na fábrica e no escritório só se pode escapar adaptando-se a ele durante o ócio. Eis aí a doença incurável de toda diversão. O prazer acaba por se congelar no aborrecimento, porquanto, para continuar a ser um prazer, não deve mais exigir esforço e, por isso, tem de se mover rigorosamente nos trilhos gastos das associações habituais (HORKHEIMER; ADORNO, 1985, p. $128 ; 1997$, p. 158-159).

Essa última assertiva nos afirma que é preciso distrair-se fora dos momentos de trabalho para que se possa suportá-lo e que isso é, afinal de contas, um exercício de celebração da dor, do sacrifício, do sofrimento. Ora, há um momento de verdade na inverdade do lazer: sem ele, ou sem algum outro narcótico, não suportaríamos o trabalho e suas asperezas. Resta saber o quanto aprendemos a gostar dessa experiência de danificação, sobretudo quando ela nos faz esquecer - ou mesmo gostar -, anestesicamente, do sofrimento.

\section{LAZER À LUZ DO NOSSO TEMPO}

Atenho-me, rapidamente, a quatro questões exemplares de nossas experiências danificadas com a indústria cultural contemporânea. Uma das características essenciais da indústria cultural é a mescla de informação e entretenimento, ambos produtos para o consumo. Quando assistimos a um jornal televisivo, somos "informados" sobre diversas situações: um gatinho tirado do telhado pelo corpo de bombeiros, o número de mortos em mais um capítulo do desastre cotidiano da Palestina, os artilheiros do campeonato brasileiro de futebol. Tudo isso está equiparado, está no mesmo plano, cumprindo, sobretudo a função de entreter (pela condição fragmentária como se apresentam os fatos, pela 
não hierarquia dos fenômenos, pela falta de uma discursividade mais elaborada, pelas expressões faciais dos apresentadores e outras).

Nesse quadro, podemos ter como exemplo o caso da última Copa do Mundo de Futebol. Tanto o Jornal Nacional quanto o Jornal da Globo, ambos da emissora mais abrangente e importante do Brasil, eram transmitidos, em parte, do Japão e da Coréia, noticiando a Copa e principalmente o selecionado brasileiro. Ora, como a Rede Globo detinha o monopólio de transmissão das partidas da Copa em canal aberto, a informação, que já se misturara com o entretenimento pela própria natureza do espetáculo, passou a mesclar-se, também, com o produto que a própria empresa vendia, os jogos na íntegra.

A arena política contemporânea, por sua vez, é um produto da indústria cultural e um resultado dos grandes cânones da propaganda: a emoção, a comoção, o caráter imprescindível com os quais os candidatos e governantes se apresentam, sua "infalibilidade" e "superioridade moral", a retórica demiúrgica, o "olho no olho", que facilmente vira olho por olho e dente por dente.

O grande paradigma da propaganda política contemporânea, também no Brasil, parece ser $O$ triunfo da vontade, de Leni Rifensthal, filme-documentário sobre a reunião do Partido Nacional-socialista em 1934. Nele, a política não é propriamente documentada, mas é protagonizada como espetáculo, como obra de arte total. Lembre-se aqui que Leni Rifensthal, a cineasta tornada oficial pelo nazismo, "criou" não apenas o paradigma da propaganda política moderna, mas também o das transmissões televisivas, com o projeto Olympia - Festa do povo, Festa da beleza. A política contemporânea coincide com o eclipse da razão, se podemos aqui tomar emprestado o marcante título de um dos principais livros de Max Horkheimer (1996), e não é casual a presença, mesmo entre aqueles que outrora se colocaram como apóstolos das luzes, de políticos portadores de projetos obscurantistas, irracionais - projetos de poder que fazem arrepiar os que ainda levam a sério as promessas do Iluminismo, de uma sociedade laica, secular, de livres pensadores, que ainda entenda a ação política como algo que se desenvolve no espaço público, que resiste aos processos de deterioração pelo qual este último passa.

Contudo, há uma louvável expectativa na formação crítica do espectador. Dela faz parte a esperança de que alguém que assiste aos 
programas poderia refletir criticamente sobre aquilo que atua sobre seus sentidos; que seria capaz de perceber, por exemplo, o merchandising da novela ou do jogo de futebol. Trata-se de uma expectativa plausível, e o espectador esclarecido e atento pode perceber estes esquetes e comentários nas transmissões e programas televisivos. Mas corremos novamente o risco de considerar como razoável aquilo que só o é no sentido de uma racionalidade vinculada aos meios fetichizados, deixando de observar que o próprio evento é um produto dos esquemas da indústria cultural, que não foi por ela "tomado" - como se o jogo de futebol, em sua "grandeza", não fosse ele mesmo um produto banalizado.

Como já disse anteriormente, não se pode pensar o esporte como algo que foi absorvido pela indústria do entretenimento, mas como produto dela. Não tivesse a sociedade ocidental mudado tanto depois da II Grande Guerra, com a explosão da indústria cultural no mundo todo, não teríamos o esporte como hoje o conhecemos. Notemos, por exemplo, como o narrador esportivo da Rede Globo, Galvão Bueno, acelera o ritmo do jogo de futebol em suas locuções e o quanto isso determina nossa percepção. Verifiquemos também o tipo de "debate" que se faz presente nas mesas-redondas dos programas sobre futebol: se é "ético" ou não um jogador fazer "embaixadinhas", se um futebolista é ou não um "bom menino", se ajuda ou não os seus parentes, se "ama" ou não o seu clube ou seleção brasileira de futebol; notemos também o tipo de produção do outro como inimigo, tal como as narrativas futebolísticas o fazem ao erigir esse ou aquele clube ou país à condição de objeto de nossa hostilidade - a República Argentina e seu selecionado de futebol, por exemplo.

Compõe esse mesmo processo o desejo, algo estranho, de afirmação étnica pela indústria cultural. Trago o exemplo de um documentário sobre a participação de negros brasileiros em novelas e minisséries de televisão, muito pequena e freqüentemente em papéis secundários ou depreciativos. Trata-se, no mais das questões, do excelente documentário A negação do Brasil, cujo livro correspondente traz o mesmo título (ARAÚJO, 2000). É fato que assim acontece, mas não deixa de surpreender o caráter inquestionável da reivindicação em mais e mais participar justamente daquilo que nos degrada como expressão cultural. A presença na indústria cultural se torna critério de autonomia social. Mas, há um momento de verdade nessa inverdade, já que por meio da televisão se organiza a cultura nacional, ainda que isso seja feito como paródia, inclusive de si mesma. 
Chego a um último exemplo. Se vivemos sob o espectro maisque-real do fetichismo, são os ambientes assépticos dos shoppings centers os templos do consumo, assim como as grandes galerias foram os primeiros territórios das coleções de fascinantes mercadorias, produtos que enfeitiçavam as multidões que caminharam por Paris no século XIX, tal como os literatos de então retrataram e como Walter Benjamin (1997) trouxe ao estatuto de marca da modernidade. As galerias são marcos também da modernidade periférica de São Paulo, Montevidéu e Buenos Aires, metrópoles ascendentes no início do século XX.

Correspondentes aos shoppings centers como templos do consumo são as academias de ginástica e musculação, territórios de consumo de corpos em seus rituais de sacrifício (HANSEN; VAZ, 2004) e afirmação de gênero (SABINO, 2000). Não por acaso muitas academias instalam-se justamente nos shoppings centers, fazendo mesclar o próprio corpo com outras mercadorias, colocando à venda um conjunto de técnicas e outros produtos que prometem fazer alcançar um corpo idealizado, mas, por certo, muito dificilmente alcançado, como é necessário que seja nos esquemas da indústria cultural.

Como deve acontecer quando se trata de um fetichismo, registro de relações simbólicas concretas em sua feição mágica, os templos do fitness têm seus próprios rituais, exigindo disciplina própria, vocabulário, hierarquia, roupagem, gestos, sons, gostos, olhares e odores específicos. As academias de ginástica e musculação

possuem também os seus confessionários e lugares de contrição, de onde nada pode escapar desconhecido: as balanças e os espelhos, fundamentais numa sociedade na qual a imagem atingiu insuspeitada importância. $\mathrm{O}$ sofrimento do corpo não se exige mais para purificar a alma, mas o próprio corpo tornado alma deve purificar-se de seus piores males: a gordura, a flacidez e a feiúra. Não é à-toa que o quesito boa aparência se torna um distintivo importante no mercado, que começa a excluir os obesos, vítimas preferenciais da fúria persecutória dos modelos idealizados ou aceitáveis de corpo. Na sociedade brasileira, na qual a visibilidade do corpo é a própria presença da alma, essas questões atingem proporções dramáticas (VAZ, 2003, p. 66-67).

Ainda temos, nesse contexto, as revistas ilustradas para o corpo e suas orientações sobre um dever ser, sobretudo feminino. Elas apresentam um conjunto de dispositivos pedagógicos na forma de prescrições 
de séries de exercícios, dietas e fármacos para a pele e o cabelo, orientações quanto à hidratação e à exposição solar, entre outras. Para corroborar suas assertivas, há sempre a presença das promessas de resolução dos problemas em determinado prazo, o aval científico dos especialistas e a linguagem bélica que ajuda a instituir os inimigos: gorduras, quilos extras, culote, centímetros que devem ser "detonados", "destruídos", "atacados". Mas, para não deixar dúvida, são apresentadas imagens de mulheres cujo belo corpo é sinônimo de sucesso e felicidade - esta estampada nos sorrisos tecnicamente perfeitos. ${ }^{2}$

\section{DIVERSÃO E MAQUINIZAÇÃO DO CORPO}

Gostaria de me referir a uma última questão, importante para o debate sobre indústria cultural e lazer, que é um significado do riso. Por um lado, ele é a mostra, mediada pela indústria cultural, da dominação do aparato pulsional, daquilo que faz "divertir" pela humilhação de tudo o que é apresentado como fraco, abjeto, dissonante e que, portanto, deve ser destruído porque nos traz medo; por outro, é uma manifestação espontânea, que mostra nossa impossibilidade de um total controle sobre nosso corpo, sobre nossa natureza interna: ${ }^{3}$

Se o riso é até hoje o sinal da violência, o prorrompimento de uma natureza cega e insensível, ele não deixa de conter o elemento contrário: com o riso, a natureza cega toma consciência de si mesma enquanto tal e se priva assim da violência destruidora (HORKHEMER; ADORNO, 1985, p. 78; 1997, p. 96-97).

Cito aqui uma reflexão feita por Slavoj Zizek (2003) sobre a caixa de riso, invenção já antiga, que há três anos viu seu criador morrer: a caixa produz um som que emite risadas em situações que devem ser consideradas engraçadas nas comédias - uma atualização das carpideiras pagas, por algum parente rico do morto, para chorar em velórios e enterros, para que aquele tenha tempo de cuidar de algo "mais importante", como o espólio do falecido, por exemplo.

Por incrível que pareça, a invenção de Douglass provou que o mesmo mecanismo "primitivo" também funciona em nossas sociedades altamente desenvolvidas: quando, à tarde, chego em casa, exausto demais 
para me dedicar a uma atividade útil, eu simplesmente aperto o botão da TV e assisto a "Cheers", "Friends" ou a outro seriado; mesmo se eu não rir, mas apenas olhar fixamente para a tela, cansado depois de um dia difícil de trabalho, eu não obstante me sinto reconfortado depois do programa - é como se a tela de TV estivesse literalmente rindo no meu lugar, em vez de mim... Antes de se acostumar com a "risada enlatada", entretanto, há geralmente um breve período de desconforto: a primeira reação ao mecanismo é de choque, uma vez que é difícil aceitar que uma máquina em algum lugar possa "rir por mim" - há algo inerentemente obsceno nesse fenômeno. No entanto, com o tempo, acostuma-se a isso e o fenômeno é sentido como sendo "natural". É justamente isso que perturba tanto na "risada enlatada": meus sentimentos mais profundos podem ser radicalmente exteriorizados, eu posso literalmente "rir e chorar através do outro" (ZIZEK, 2003, p. 16).

O riso pode nos lembrar a natureza em nós, uma dimensão que compartilhamos com o indeterminado. O que a risada enlatada nos sugere, no entanto, é que quando somos consumidores passivos, ainda não estamos totalmente reificados, mas a ameaça autêntica é nem isso mais podermos ser: as novas mídias podem fazer tudo por nós - babás eletrônicas, sexo digital, videocassete, computadores portáteis, internet, entre outros. Nossa autêntica experiência passiva é substituída pela possibilidade de mais e mais irracional e frenética atividade, como diz Slavoj Zizek (2003). Nos espaços e tempo de lazer, quem sabe.

Os processos de maquinização do corpo e de destruição da experiência - louvados por alguns apenas como novas possibilidades tecnológicas, talvez nos levem a algo que o Marquês de Sade chamou de feliz apatia: nem mesmo rir precisaremos, porque o aparato se encarregará disso. Teremos mais tempo para o trabalho e para o lazer que cultivamos - e, talvez, infelizmente, fiquemos mais satisfeitos.

\section{Reflections on leisure: notes on the pedagogy of the culture industry}

\section{ABSTRACT}

The present text deals with a few elements of the relation between the culture industry and leisure, the latter being understood as an undetachable part of the former. In order to do so, this article brings, in its first part, some of the origin of the concept of culture industry as it was developed by Theodor Adorno and Max Horkheimer. It then gives a few examples in which culture industry structures materialize - the broadcasting of the 
World Cup 2002, the contemporary political arena, a documentary film, the "perfect body" industry - in an attempt to verify how these structures form a gruesome constellation which make us perceive the domination processes behind contemporary entertainment as "natural". In its final part, this text briefly analyzes the theme of laughter as an expression of a civilization's dialectic, a pulsional control loss which is rationally mediated, but also a sign of hope of a nonconforming nature.

KEYWORDS: leisure - the culture industry - Frankfurt School - free time - body - Theodor W. Adorno

\section{Reflexiones de pasaje sobre el ocio: notas sobre la pedagogía de la industria cultural}

\section{RESUMEN}

El presente texto trata de algunos elementos de la relación entre industria cultural y ocio, comprendiendo el segundo como parte indisociable de la primera. Para ello, el artículo retoma, en su primera parte, un poco del origen del concepto, tal como fue desarrollado por Theodor Adorno y Max Horkheimer. Enseguida, son citados algunos ejemplos em los cuales se materializan los esquemas de la industria cultural - la trasmisión de la Copa de 2002, la arena política contemporánea, un filme documentario, la industria del culto al cuerpo - para intentar verificar como esos esquemas forman una constelación macabra que naturaliza los procesos de dominación por el entretenimiento contemporáneo. Al final, el texto realiza una pequeña incursión en tema de la risa, expresión de una dialéctica de la civilización, del descontrol pulsional mediado racionalmente, sin embargo también marca de la esperanza de una naturaleza no conformada.

PALABRAS-CLAVE: ocio - industria cultural - Escuela de Frankfurt - tiempo libre - cuerpo - Theodor W. Adorno

\section{NOTAS}

1 Texto adaptado de minha intervenção em mesa-redonda no I PréConbrace Sul, realizado em Pato Branco, Paraná, em junho de 2003. Agradeço aos organizadores, especialmente a Santiago Pich, o convite e a acolhida durante o evento. O texto guarda o tom eventualmente mais polêmico da palavra falada, resultado de pesquisas financiadas pelo CNPq e pela FAPESC.

2 As prescrições para um dever ser mulher não são uma exclusividade do tempo presente. As pesquisas de Sant'anna (1995), Goellner (2000) e Albino e Vaz (2005), que trabalharam com diferentes fontes, demonstram certa popularização dos dispositivos pedagógicos em revistas ou jornais ilustrados da primeira metade do século XX. 
3 "Rimos do fato de que não há nada de que se rir. O riso, tanto o riso da conciliação quanto o riso do terror, acompanha sempre o instante em que o medo passa. Ele indica a liberação, seja do perigo físico, seja das garras da lógica. O riso da liberação é como o eco do fato de ter escapado à potência, o rio mau vence o medo passando para o lado das instâncias que inspiram temor." (HORKHEIMER; ADORNO, 1985, p.131; 1997, p. 162).

\section{REFERÊNCIAS}

ADORNO, T. W. Freizeit. In: Stichworte. Kritische Modelle 2. Frankfurt am Main: Suhrkamp, 1978. p. 57-67.

. Tempo livre. In: trópolis: Vozes, 1995. p. 70-82. . Palavras e sinais: modelos críticos 2. Pe. Resumé über kulturindustrie. In: . Gesammelte Schriften 101. Frankfurt am Main: Suhrkamp, 1997a. p. 337-345.

. Kulturkritik und Gesellschaft. In: . Gesammelte Schriften 10-1. Frankfurt am Main: Suhrkamp, 1997b. p. 11-30.

. Minima Moralia: Reflexionen aus der beschädigten Leben. In: . Gesammelte Schriften 4. Frankfurt am Main: Suhrkamp, 1997c.

ALBINO, B. S.; VAZ, A. F. Educação do corpo feminino no Jornal Dia e Noite (1940/1941). In: CONGRESSO BRASILEIRO DE CIÊNCIAS DO ESPORTE, 9., 2005, Porto Alegre. Anais... Porto Alegre: Colégio Brasileiro de Ciências do Esporte, 2005. p. 2533-2537.

ARAÚJO, J. Z. Negação do Brasil: o negro na telenovela brasileira. São Paulo: Senac, 2000.

BENJAMIN, W. Charles Baudelaire. Frankfurt am Main: Suhrkamp, 1997.

HANSEN, R.; VAZ, A. F. Treino, culto e embelezamento do corpo: um estudo em academias de ginástica e musculação. Revista Brasileira de Ciências do Esporte, Campinas, v. 26, n. 1, p. 135-152, 2004.

HORKHEIMER, M. Eclipse of reason. New York: Continuum, 1996. 
GOELLNER, S. V. Mulheres em movimento: imagens femininas na Revista Educação Physica. Educação e Realidade, Porto Alegre, v. 2, n. 25, p. 77-94, jul./dez. 2000.

HORKHEIMER, M.; ADORNO, T. W. Dialética do esclarecimento. Rio de Janeiro: Zahar, 1985.

. Dialektik der Aufklärung: Philosophische Fragmente. Gesammelte Schriften 3. (Adorno). Frankfurt am Main: Suhrkamp, 1997. p. 7-296.

SABINO, C. Musculação: expansão e manutenção da masculinidade. In: GOLDENBERG, M. (Org.). Os novos desejos: das academias de musculação às agências de encontros. Rio de Janeiro/São Paulo: Record, 2000. p. 61-103.

SANT'ANNA, D. B. Cuidados de si e embelezamento feminino. In: (Org.). Políticas do Corpo. São Paulo: Estação Liberdade, 1995. p. 121-139.

VAZ, A. F. Corpo, educação e indústria cultural na sociedade conteporânea: notas para a reflexão. Pro-posições, Campinas, v. 14, n. 2, p. 61-75, 2003.

ZIZEK, S. A risada enlatada. Folha de São Paulo, São Paulo, 1 jun. 2003. Mais!, n. 27087, p. 16.

Recebido: 10 de outubro de 2005 Aprovado: 10 de dezembro de 2005

Endereço para correspondência: Universidade Federal de Santa Catarina

Centro de Ciências da Educação Departamento de Metodologia de Ensino Caixa Postal 476 - Trindade Florianópolis - Santa Catarina CEP 88040-900 E-mail: alexfvaz@uol.com.br. 